\title{
O PRELÚDIO DA ESCRITA DE UMA DISSERTAÇÃO
}

\section{THE WRITING OF A DISSERTATION PRELUDE}

Kethlen Kohl 


\section{Resumo}

Este texto é uma reflexão pessoal sobre os métodos e caminhos para escrever minha dissertação de mestrado, um prelúdio da escrita de minha dissertação. Nele abordo alguns problemas encontrados durante o processo de pesquisa e de escrita, assim como alguns apontamentos para a construção do trabalho final de mestrado. Palavras-chave: Escrita, disserta- Methods ção, métodos.

\section{Abstract}

This text is a reflection personal about methods and paths to write my master's thesis a prelude of my master's thesis writing. In it i discuss some problems encountered during the process of research and writing, As some notes paragraph construction labour masters final.

Keywords: Writing, Master Thesis,

ISSN: 2175-2346 


\section{INTRODUÇÃO}

Neste texto procuro pensar sobre os caminhos da escrita de uma dissertação de mestrado. Isto significa que vou escrever sobre algo que nunca fiz, pois nunca desenvolvi uma dissertação. Mas, como pode alguém escrever sobre aquilo que nunca fez? Bom, acredito que na escrita pode tudo, até mesmo escrever sobre o que não viveu ou o que não fez. Sobretudo, este texto servirá também como um experimento, uma preparação para escrever minha dissertação. Será "o prelúdio da escrita de uma dissertação".

Primeiro quero esclarecer que se trata de uma dissertação do campo de Teoria e História da Arte. Deste modo, algumas coisas podem estar dedicadas apenas a esta área do conhecimento. Diante do desafio de esclarecer os caminhos para a escrita da dissertação, procurei usar algumas referências que considero importantes e também explicitar as minhas experiências acadêmicas sobre a pesquisa (coisas que escuto de professores desde minha graduação e pequenas práticas desenvolvidas neste período). Para entender este tipo de trabalho, nada melhor do que começar com uma dissertação já concluída que serve como ponto de partida. Assim, reviso a dissertação de mestrado de Vanessa Schults intitulada "O lugar da publicação: artistas e revistas", como uma de minhas referências iniciais. Depois sigo através de uma interlocução com os artigos que compõe o livro "A bússola de escrever desafios e estratégias na orientação e na escrita de teses e dissertações", como o artigo "A 'revisão da bibliografia' em teses e dissertações: meus tipos inesquecíveis o retorno" de Alda Judith Alves e o artigo "Viver a tese é preciso" de Maria Ester de Freitas. Diálogo com o texto "Escrever" de Marguerite Duras e um vídeo da pesquisadora Debora Diniz com o tema "As travas da escrita". Estas são algumas referências básicas que estruturam a linha de pensamento presente neste texto.

Escrever sobre como fazer uma dissertação não é uma tarefa extremamente difícil, pois já tive algumas disciplinas de metodologia, revirei os manuais e livros de pesquisa, visualizei vídeos no Youtube e escutei vários professores e colegas falarem sobre suas experiências. No entanto, fazer a pesquisa e transformá-la em escrita parece algo bastante difícil e requer horas de dedicação e persistência. As coisas não são tão claras como nos manuais, não são simples como achamos. Construir as coisas leva tempo e para isso também é necessário paciência, força e persistência.

Maguerite Duras disse que escrever é estar só e que "A solidão da escrita é uma solidão sem qual o escrito não se produz, ou se esfarela, exangue de procurar escrever" (DURAS, Maguerite, 1994, p. 14). Esta solidão é algo que está presente na maior parte da construção do pensamento e principalmente no momento de traduzir o pensamento para escrita. Sendo assim, estou ciente de que será preciso ter um espaço em minha casa onde poderei ficar confortável com minha solidão.

Acrescento ainda as palavras de Maria Ester de Freitas, para entender como o processo da escrita pode ser difícil, pois a dissertação "é um projeto especial, sem demérito aos demais, que mobiliza todas as forças do sujeito, pois trata-se de uma tarefa anti-social e excludente desestabilizadora de certezas intelectuais, comportamentais e emocionais, desenvolvida a longo prazo" (FREITAS, Maria Ester, 2002, p. 
216). Então, imagino que muitas pessoas não entenderão diversas coisas que acontecerão comigo no período de escrita. O mundo e as coisas que nele vivem não param quando eu estiver escrevendo, acontecerão festas que não poderei ir e também outras diversões que terei que negar e dizer "não, preciso escrever a dissertação". No entanto, escrever a dissertação se refere a uma escolha, que por vezes pode ser muito prazerosa e por vezes, difícil. Para enfrentar isto, procuro considerar as etapas que descrevo adiante.

\section{A constituição do objeto}

Para poder escrever uma dissertação, primeiramente terei que ter um projeto de pesquisa com itens bem delimitados, já que ele é a base do trabalho. Neste projeto deverá estar explicito os principais pontos de partida: o meu objeto de pesquisa e os objetivos.

O objeto é basicamente a origem de tudo que irei escrever. O meu objeto já foi definido, são algumas obras de arte que foram selecionadas por mim. A partir delas defini o meu tema "interdição e o consentido na história da arte ". O objeto deve ser uma escolha pessoal, algo que faça sentido, que desperte a curiosidade e muito interesse. Por exemplo, na dissertação de Vanessa Schultz, os objetos dela são "peças gráficas de baixo custo e alta reprodutibilidade, feitas por artistas visuais a partir das décadas de 1960-70" (SCHULTZ, Vanessa, 2008, p.12). Como Vanessa trabalhava com peças gráficas e com diagramação de revistas, ao fazer esta escolha pode associar algo que lhe interessava e também ajudava em sua profissão.

O objeto desdobra-se em objetivo geral, pois é ele que descreve o que eu pretendo fazer e também o que delimita a pesquisa. É assim no trabalho de Vanessa, ela propôs, "abordar como o uso experimental de diferentes linguagens e a tecnologia de geração de múltiplos impressos colaboraram para a instauração de tais peças gráficas/publicações como espaços expositivos alternativos" (SCHULTZ, Vanessa, 2008, p.12). Ela precisou criar um objetivo para a pesquisa pois a escrita da dissertação é a tentativa de encontrar respostas para o objetivo geral.

Existem também os objetivos específicos que são algumas etapas que irei percorrer para conseguir concluir o objetivo geral. Estes objetivos são mais voltados para os detalhamentos da pesquisa, eles vão de encontro com a metodologia que são as formas como vou proceder. A metodologia é crucial para o andamento da escrita, pois ela é a descrição da ação, como serão feitas minhas ações para alcançar os objetivos. Em minha pesquisa, sei que vou abordar as obras de arte usando uma metodologia de análise anacrônica, assim usarei imagens de diversas temporalidades. Deste modo, não haverá um recorte temporal em minha dissertação. Vanessa decidiu trabalhar com um recorte temporal, em sua metodologia escolheu garimpar várias publicações de artistas dos anos 60-70, analisou todas e também fez uma ação reflexão sobre o espaço gráfico da publicação.

Ao ouvir professores e colegas falarem sobre suas pesquisas, percebo que os métodos e outras particularidades do projeto podem se modificar no começo da escrita da dissertação, ou até mesmo quando estamos coletando dados. O método é 
muito importante, principalmente para que exista um fio condutor em minha pesquisa, sem ele caminharei no escuro.

\section{A revisão de Bibliografia}

A revisão bibliográfica é extremamente relevante para o desenvolvimento do trabalho. Ela pode ajudar a delimitar os objetivos da pesquisa. Mesmo que eu já tenha os objetivos ou tema recortado a revisão vai servir para dar consistência a dissertação. Para entender melhor as questões da revisão bibliográfica utilizo o texto "A revisão da bibliografia em teses e dissertações: meus tipos inesquecíveis" de Alda Judith Alves. A autora salienta em seu texto que a má qualidade da revisão de literatura compromete o estudo, e muitos pesquisadores tendem a não dar tanta importância a este processo. A revisão se torna algo superficial e é mal utilizada nos trabalhos acadêmicos.

Além de dar consistência ao trabalho acadêmico a revisão serve como uma forma de me situar no que acontece na comunidade cientifica, em relação ao tema que está sendo pesquisado, ou outras produções pertinentes na escrita. Através dela posso selecionar teorias ou evitar outras que forem impróprias para minha linha de raciocínio. Posso pensar no que já existe de produção sobre o tema, evitando que as problemáticas sempre se repitam. Alda sugere a revisão bibliográfica como ponto de partida da pesquisa, " sempre que houver revisões de bibliografia recentes e de boa qualidade sobre o tema é conveniente começar por elas e a partir delas, identificar estudos que, por seu impacto na área, e/ou proximidade com o problema a ser estudado" (ALVES, Alda Judith, 2002, p.28).

Conhecer os escritores e suas produções nos ajudam a entrar em diálogo com outras produções acadêmicas e literárias. Fazer uma boa revisão bibliográfica e procurar por pensadores que estudam os mesmos temas é importante para que eu saiba o que já foi produzido.

Com essas fontes eu irei fazer uma conversa entre meus interesses e de outros pesquisadores. Pretendo usar livros como "diante da imagem" e a "pintura encarnada" de Didi Huberman. Estes livros ajudarão a analisar as obras escolhidas de minha pesquisa e podem servir de base metodológica. As obras que irei analisar expelem alguns conceitos e problemáticas filosóficas que terei que refletir, para isso percorro diversos livros como: "História da Sexualidade I: A Vontade de Saber", de Michel Foucault; "Manifesto Contrassexual", de Beatriz Preciado; "O Erotismo", de Georges Bataille; "De Pueris (Dos Meninos) e A Civilidade Pueril", de Erasmo de Roterdã, entre outros. Estas são as minhas referências base, com o aprofundamento da pesquisa e da escrita haverá outras mais.

Para que o diálogo entre as fontes e as ideias de outros autores seja consistente, deverá existir um critério na análise e intepretação destas referências. É importante ler e reler as teorias e os conceitos, para poder criticar e ter o melhor aproveitamento do trabalho do pensador que for analisar.

\section{A relação com as fontes}


Após ter feito o projeto de pesquisa e a revisão bibliográfica, muitos pesquisadores partem para o espaço onde está o objeto. Esta etapa é direcionada ao campo de pesquisa, espaço onde vou encontrar documentos, registrar ações, fazer entrevistas, garimpar todas as fontes para poder escrever a dissertação. Só se pode iniciar uma escrita cientifica após ter elementos para montar a estrutura textual.

Como meu objeto de pesquisa são obras de arte, preciso coletar todos os dados possíveis sobre elas. Estas informações podem estar em catálogos, registros de museu ou galerias, também poderei fazer entrevistas com artistas ou curadores. Estes são os espaços onde se pode obter informações.

Meu objeto está armazenado em meu computador como um arquivo de imagem da obra, e não a obra real. O ideal seria observar ao vivo as obras que irei estudar, isso sem dúvidas proporcionaria uma outra relação com a fonte. A relação com a obra é importante pois é possivel perceber detalhes, compreender a dimensão da obra, pensar para que espaço ela foi feita e sentir coisas que só é possível vendo o objeto real. Infelizmente, entrarei em contato com poucas obras ao vivo, pois a maioria delas está em lugares de difícil acesso.

No campo da história da arte é muito comum acontecer alguns problemas no momento de ir ao campo de pesquisa. Nem todas as obras estão disponíveis à visitação, é preciso ter autorização para ter acesso a obra. Aquelas que podem ser vistas nem sempre podem ser fotografadas, existe a proibição de reprodução da imagem até mesmo para o estudo. Com isso, muitas vezes os catálogos, livros e a internet acabam sendo os campos de pesquisa mais acessiveis para o historiador da arte.

Além de olhar as obras estudadas é importante recolher o máximo de informações sobre estas, como data da criação, autor, data da exposição, qual o acervo onde está, quais materiais utilizados, entre outras. Estas informações ajudam a responder duvidas que surgem durante a escrita ou até mesmo definir a forma de análise que será usada.

As relações com as fontes são importantíssimas, pois é nesse momento que surgem questões, direcionamentos para a pesquisa. Aqui é possível encontrar os pontos que se intercruzarão na escrita da dissertação. É nesse momento que vou me relacionar com o objeto pesquisado e ele é necessário para que o trabalho tenha consistência. Este momento irá definir minha escrita, pois acredito que assim surgem respostas e indagações sobre o objeto.

\section{As travas da escrita}

Após eu me aproximar das fontes e tentar definir melhor o foco do objeto, passo para a fase inicial da escrita da dissertação. No decorrer da vida acadêmica já ouvi muitos estudantes passarem por esta etapa falando das "travas da escrita". A maioria deles dizem não conseguir sair das três primeiras linhas e o problema se repete em várias tentativas de escrita. Me parece que este processo é muito complexo e recorrente em qualquer produção deste nível de dificuldade. Ultimamente tenho visto um 
canal no Youtube chamado "Quinquilharias"1 , da pesquisadora e antropóloga Debora Diniz que fala justamente sobre as "travas na escrita" e apresenta três dicas para vencer esta trava.

A primeira dica é que é preciso escrever todos os dias, não importa o quanto, e não importa o que, deve-se escrever qualquer coisa. Uma referência a uma leitura, um pensamento, pequenas coisas sobre minha pesquisa, devaneios, etc. Preciso criar uma espécie de diário de campo, onde deverei escrever todos os dias.

A segunda dica é escrever para os outros, criar um grupo de apoio de pessoas que possam ler meus textos e que eu possa ler os textos destas pessoas, que estejam no mesmo momento de escrita que eu. A ideia é transformar a experiência da escrita também em experiência de leitura. Desta forma, eu vou ler outros trabalhos e os outros irão ler minhas escritas. Segundo Diniz, a escrita tem que ser algo capaz de comunicar, por isso é importante que outras pessoas leiam meu trabalho.

A terceira dica é não imaginar minha dissertação como um monstro de 400 páginas, devo pensar nela como 80 páginas, pois então posso ir produzindo aos poucos. Devo pensar nela como uma resenha, um artigo, um ensaio, coisas pequenas que podem ser publicadas aos poucos. Assim, vou construindo a dissertação e aos poucos me descobrindo como escritora.

Estas dicas que Debora Diniz propõe são muito interessantes e acredito que elas podem funcionar. Estou colocando estas dicas em práticas aos poucos, confesso que ainda não estou escrevendo todos os dias, mais procuro anotar meus pequenos pensamentos, e escrever sobre as coisas que estou lendo. Tento seguir o lema de Diniz, " escrever aos poucos mais sempre".

\section{CONSIDERAÇÕES FINAIS}

Procurei neste texto fazer uma reflexão e o exercício sobre a escrita da dissertação, buscando fontes, experiências e demais alternativas, fazendo um prelúdio do meu processo de escrita. Quero lembrar aqui no final deste texto de uma figura muito importante na produção da dissertação, o orientador. Pois diante dos caminhos de indecisão você pode contar com ele. A maioria deles já teve diversas experiências com pesquisa e escrita, desta forma podem ajudar em todas estas etapas que descrevi no texto. Mas, a produção só depende de quem está pesquisando e escrevendo. Durante o período de pesquisa e escrita surgirão várias possibilidades e caminhos para construir a dissertação, as leituras levarão seu trabalho a outros caminhos. A medida que se descobre novas coisas na pesquisa, os métodos podem mudar. Sendo assim, penso que cada pessoa se organiza de maneira diferente, nem todas se adaptam a determinados métodos. Por fim, o que vale é experimentar, se arriscar e se dedicar a pesquisa e a escrita. Só assim poderei voltar ao que escrevo agora como quem visita um lugar onde algo muito importante teve início.

1AS TRAVAS da escrita. Debora Diniz. Local: São Paulo, 2016.3 minutos e 47 segundos. Disponivel em: https://www.youtube.com/watch?v=LKXgsxMFQy4 Acesso em: mai. 2016. 


\section{REFERÊNCIAS}

ALVES, Alda Judith. A "revisão da bibliografia" em teses e dissertações: meus tipos inesquecíveis o retorno. In: A bússola de escrever desafios e estratégias na orientação e na escrita de teses e dissertações. Florianópolis, 2002.

DURAS, Marguerite. Escrever. Trad. de Rubens Figueiredo. São Paulo: Ed. Rocco.

FREITAS, Maria Ester de. Viver a tese é preciso. In: A bússola de escrever desafios e estratégias na orientação e na escrita de teses e dissertações. Florianópolis, 2002. AS TRAVAS da escrita. Debora Diniz. Local: São Paulo, 2016.3 minutos e 47 segundos. Disponivel em: https://www.youtube.com/watch?v=LKXgsxMFQy4 Acesso em: mai. 2016.

SCHULTZ, Vanessa. Lugar da publicação: Artistas e revistas. 2008. 176f. Dissertação (Mestrado em Artes Visuais) - Centro de Artes Universidade do Estado de Santa Catariana, Florianópolis. 2008. 